\title{
Enfisema pulmonar intersticial unilateral en un recién nacido
}

\section{Unilateral interstitial pulmonary emphysema in a newborn}

\author{
Osmany Martínez-Lemus, * Jorge Alexis Pérez-González,* \\ Silvia Evelyn Jiménez-Abreu, ${ }^{\ddagger}$ Haydeé Rodríguez-Díaz ${ }^{\ddagger}$ \\ * Especialista de segundo grado en Neonatología; ${ }^{\ddagger}$ Especialista de primer grado en Neonatología. \\ Hospital General Docente “Iván Portuondo”. San Antonio de los Baños, Artemisa. Cuba.
}

\section{RESUMEN}

Objetivo: Dar a conocer la evolución de una recién nacida (RN) con enfisema pulmonar intersticial (EPI) unilateral que requirió ventilación selectiva del pulmón contralateral. Presentación del caso: Se trata de RN femenino de 32 semanas de gestación, que presentó síndrome de dificultad respiratoria (SDR), por lo que requirió ventilación mecánica. Al segundo día de vida presentó EPI intersticial unilateral izquierdo. Como tratamiento para esta complicación, se empleó ventilación de alta frecuencia oscilatoria, así como posicionamiento del neonato sobre el lado afectado, sin lograr mejoría. Después se utilizó ventilación selectiva del pulmón contralateral durante 48 horas, lográndose la resolución total del enfisema. Conclusión: El EPI es una complicación grave en los RN. El empleo de ventilación selectiva al pulmón contralateral es una estrategia que puede ayudar a su resolución.

Palabras clave: Recién nacido, prematuro, enfisema pulmonar intersticial, ventilación selectiva.

\section{INTRODUCCIÓN}

El síndrome de fuga aérea pulmonar se define como el escape de aire del árbol traqueobronquial hacia localizaciones donde normalmente no está presente, lo cual puede producir enfisema pulmonar intersticial (EPI), neumotórax, neumomediastino, neumopericardio,

\begin{abstract}
Objective: To describe the clinical outcome of a newborn (NB) with unilateral pulmonary interstitial emphysema (PID) who required selective ventilation of the contralateral lung. Case presentation: This is a 32-week gestation female newborn, who presented respiratory distress syndrome (RDS), requiring mechanical ventilation. On the second day of life, she presented left unilateral interstitial PID. Highfrequency oscillatory ventilation was used as treatment for this complication, as well as positioning of the newborn on the affected side, but there was no improvement. Subsequently, after selective ventilation of the contralateral lung was used for 48 hours total resolution of the emphysema was achivied. Conclusion: PID is a serious complication in newborns. The use of selective ventilation to the contralateral lung is a therapeutic alternative for its resolution.
\end{abstract}

Keywords: Newborn, premature, pulmonary interstitial emphysema, selective ventilation.

enfisema subcutáneo, neumoperitoneo o embolismo gaseoso masivo. ${ }^{1}$

EPI es un síndrome de fuga aérea en el cual se produce disección del aire hacia el intersticio pulmonar, a causa de la ruptura del epitelio respiratorio. ${ }^{2,3}$ En los recién nacidos $(\mathrm{RN})$ se estima que esta condición afecta a $10 \%$ de los pretérminos menores de 30 semanas de

Correspondencia: Osmany Martínez-Lemus, E-mail: osmanyml84@nauta.cu

Citar como: Martínez-Lemus O, Pérez-González JA, Jiménez-Abreu SE, Rodríguez-Díaz H. Enfisema pulmonar intersticial unilateral en un recién nacido. Rev Mex Pediatr. 2021; 88(4): 159-162. https://dx.doi.org/10.35366/102782 
edad gestacional con síndrome de dificultad respiratoria (SDR) y que es más frecuente conforme disminuye el peso corporal. Generalmente es bilateral, aunque puede ser unilateral o confinado a un lóbulo pulmonar. ${ }^{3,4}$

Aunque puede ocurrir de forma espontánea, es más frecuente cuando los $\mathrm{RN}$ están bajo ventilación mecánica (VM). ${ }^{5}$ Los factores de riesgo para que ocurra son: bajo peso al nacer, Apgar bajo, necesidad de reanimación, ventilación con presión positiva, presión inspiratoria elevada, volumen tidal alto, síndrome de aspiración meconial, neumonía neonatal e hipoplasia pulmonar. ${ }^{2}$ Por lo anterior, se debe sospechar $\mathrm{su}$ presencia en todo $\mathrm{RN}$ que agrave la dificultad respiratoria. ${ }^{6}$

En los casos de EPI unilateral, en la radiografía de tórax se observa hiperinsuflación unilateral que causa desplazamiento del mediastino, zonas diferenciadas de hiperclaridad redondeada y tubular distribuidas a lo largo del pulmón afectado. ${ }^{4}$ Hasta el momento, no existe un tratamiento estándar para el EPI unilateral, pero se recomienda la intubación selectiva, ventilación de alta frecuencia oscilatoria (VAFO) e incluso lobectomía quirúrgica para el enfisema lobular localizado., ${ }^{4,7}$

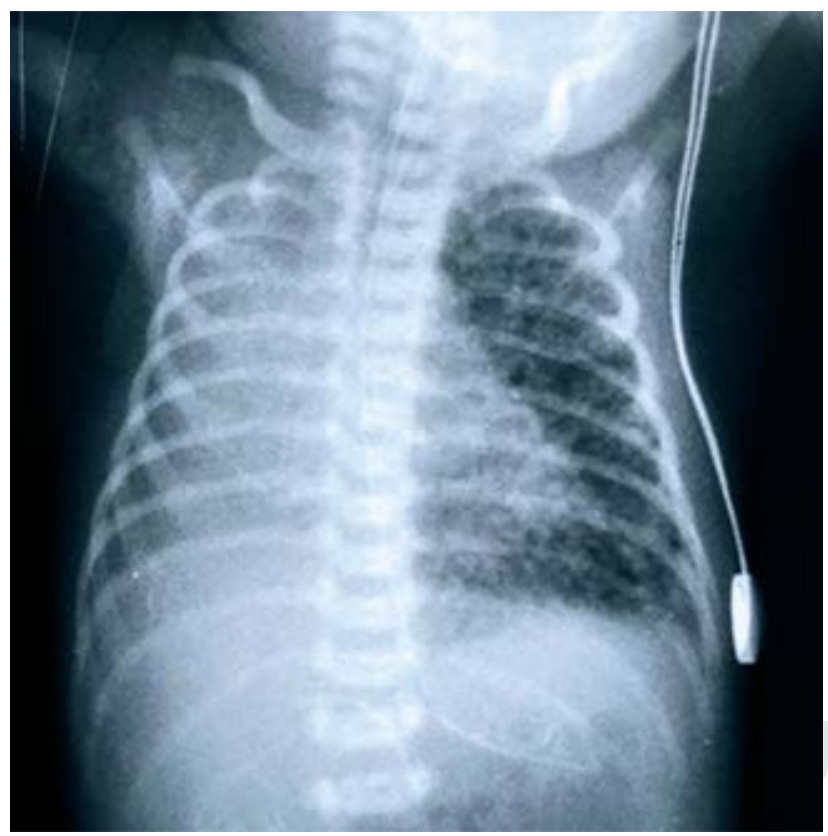

Figura 1: Se observan imágenes radiotransparentes de forma redondeada localizadas en pulmón izquierdo, con hiperinsuflación pulmonar unilateral compatibles con enfisema pulmonar intersticial unilateral.

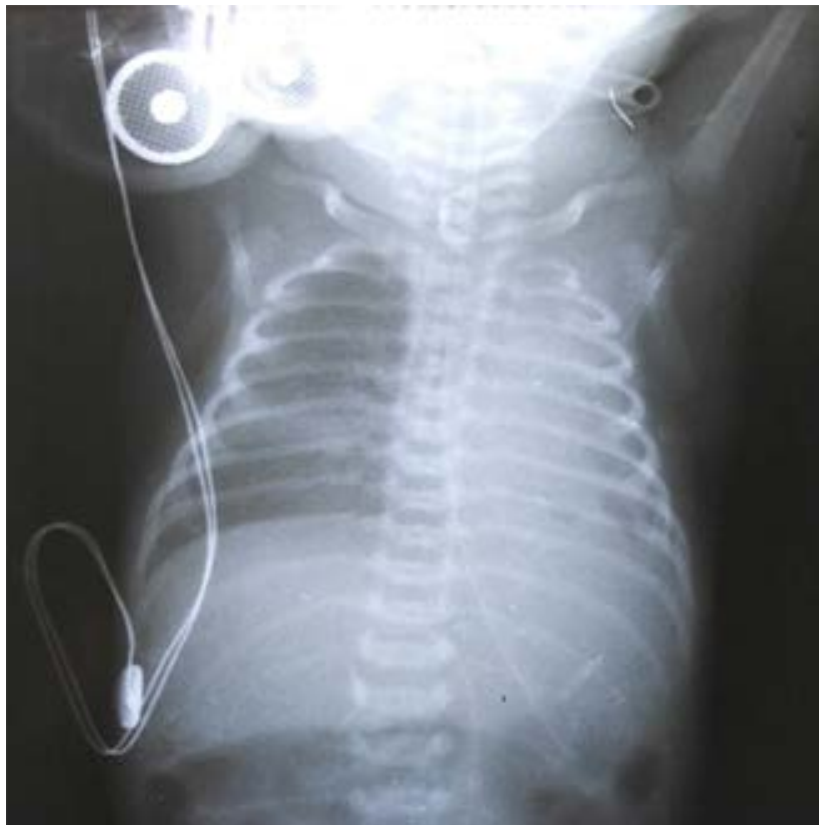

Figura 2: Radiografía posterior a la ventilación selectiva del pulmón derecho en la que se observa atelectasia total del pulmón izquierdo y mejoría de la radioopacidad reticulonodular por la aplicación de surfactante pulmonar selectivo.

Se presenta el siguiente caso clínico con el objetivo de dar a conocer la evolución de una RN con EPI unilateral, quien requirió ventilación selectiva (VS) del pulmón contralateral.

\section{PRESENTACIÓN DEL CASO}

$\mathrm{RN}$ femenino, hija de madre de 28 años, con serología VDRL no reactiva, grupo sanguíneo O positivo. Nació por cesárea a las 32 semanas de edad gestacional, con peso de 1,550 gramos y Apgar 7/8. Inmediatamente después del nacimiento, comienza con dificultad respiratoria (aleteo nasal, retracción esternal y tiraje intercostal). Se documentó acidosis respiratoria, y en Rx de tórax se observaron imágenes reticulonodulares finas y broncograma aéreo compatible con SDR del prematuro. Se procede a su intubación endotraqueal y VM en modalidad mandatoria intermitente sincronizada (SIMV); se administró surfactante pulmonar endotraqueal, a dosis de $100 \mathrm{mg} / \mathrm{kg}$.

A las ocho horas de vida, persiste con dificultad respiratoria, por lo que se incrementaron las variables ventilatorias, y se administra otra dosis de surfactante pulmonar. Sin embargo, el cuadro respiratorio no mejoró, ya que tenía hipoxemia y saturación de oxígeno 
de $83 \%$, por lo que a las $12 \mathrm{~h}$ de vida se pasa a VAFO, con $\mathrm{FiO}_{2} 50 \%$, presión media de la vía aérea (PMA) 12 $\mathrm{cmH}_{2} \mathrm{O}$, amplitud $50 \%$ y frecuencia 10 hertzios $(\mathrm{Hz})$, con lo cual mejoró la oxigenación.

A las $32 \mathrm{~h}$ de vida nuevamente se detecta hipoxemia, aumento del trabajo respiratorio y acidosis respiratoria. En una nueva Rx de tórax se muestran imágenes de EPI en pulmón izquierdo (Figura 1), por lo que se decidió colocarla en posición decúbito lateral izquierdo y se disminuye la PMA hasta $8 \mathrm{cmH}_{2} \mathrm{O}$, mejorando la oxigenación.

A las $47 \mathrm{~h}$ presenta empeoramiento, tanto de su cuadro clínico como en gasometría: $\mathrm{pH} 6.98, \mathrm{PaCO}_{2}$ 93.0, $\mathrm{PaO}_{2}$ 16.0, $\mathrm{HCO}_{3}$ 22.4, - $\mathrm{EB}$-11.7. Rx de tórax con incremento del EPI en pulmón izquierdo. Se decidió realizar VS al pulmón contralateral (derecho), dejando en atelectasia total al pulmón izquierdo, además se administró tercera dosis de surfactante pulmonar. Con todo lo anterior, las imágenes reticulonodulares del pulmón derecho presentan mejoría (Figura 2), lo mismo que los datos de dificultad respiratoria.

Durante la VS, la paciente mantuvo oxigenación adecuada, lo que permitió disminuir progresivamente la $\mathrm{FiO}_{2}$ y PMA. En total, la ventilación monopulmonar tuvo una duración de 48 h; después el tubo endotraqueal se colocó en posición correcta para ventilar ambos

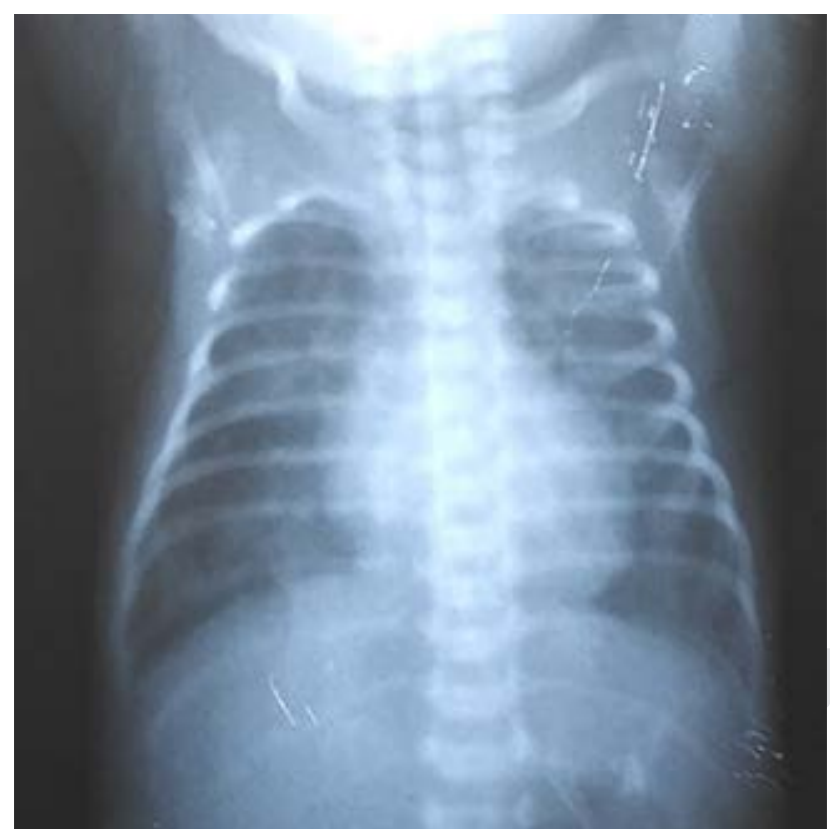

Figura 3: Se evidencia resolución total de las imágenes de enfisema pulmonar intersticial luego de 48 horas con ventilación selectiva del pulmón sano. pulmones, observándose resolución total del EPI ( $F i$ gura 3). Durante más de una semana estuvo con VM sin que presentara recurrencia del evento.

\section{DISCUSIÓN}

El desarrollo del EPI es una consecuencia común de la VM en el RN pretérmino, especialmente en aquéllos con un SDR, lo cual conlleva a empeoramiento del cuadro respiratorio. ${ }^{8}$

Por las características anatómicas del aparato respiratorio, la etapa neonatal es muy vulnerable para la aparición de escapes aéreos; en particular los RN pretérminos poseen mayor riesgo al tener un tejido conectivo perivascular más abundante y disecable.

El caso presentado fue un neonato pretérmino con SDR y necesidad de VM, quien en las primeras $48 \mathrm{~h}$ de vida presentó un EPI. Se ha descrito que el escape aéreo generalmente se presenta dentro de los primeros dos días de iniciada la VM. ${ }^{1}$ En la paciente que presentamos se utilizaron estrategias descritas en la literatura para revertir el enfisema, pero sin obtener respuesta, como el posicionamiento sobre el lado afectado y VAFO. ${ }^{7}$ Asimismo, se recomienda mantener bajos niveles de presión inspiratoria máxima y de PMA, bajo volumen corriente, $\mathrm{FiO}_{2}$ alta, así como hipercapnia. En el EPI unilateral se ha recomendado la VS del pulmón no afectado, la cual ofrece la posibilidad de la reabsorción del aire intersticial al reducir la presión alveolar del pulmón afectado a cero. ${ }^{7}$

La VS del bronquio principal derecho o izquierdo se emplea como una modalidad de tratamiento efectiva para el EPI grave desde la década de 1970. También se usa en pacientes con neumonía, infecciones por el virus sincitial respiratorio y en desgarros bronquiales. En RN es infrecuente su indicación. ${ }^{8}$ Esta alternativa resulta apropiada por la existencia de dos pulmones, y aunque el sistema respiratorio se considera una unidad funcional, al existir dos órganos independientes, es posible ofrecer tratamiento unilateral. ${ }^{9}$

Se ha sugerido que la VS tiene menos efecto sobre la $\mathrm{PaCO}_{2}$ en comparación con la $\mathrm{PaO}_{2}$, porque el pulmón ventilado elimina el $\mathrm{CO}_{2}$ compensando al pulmón no ventilado; sin embargo, el pulmón ventilado no puede captar suficiente $\mathrm{O}_{2}$ para compensar al pulmón no ventilado. ${ }^{9}$ No obstante, en la paciente que describimos, se logró un intercambio de gases adecuado, manteniendo $\mathrm{PaO}_{2}$ y $\mathrm{PaCO}_{2}$ en valores normales.

En Cuba, en el año 1998 se publicó el primer caso de un RN con EPI tratado con VS, el cual tenía 27 semanas de edad gestacional y 750 gramos de peso. 
Con esta intervención, a las 48 h hubo resolución total del escape aéreo, similar al caso presentado. ${ }^{10}$ En otro estudio publicado en Brasil, ${ }^{11}$ la VS también resultó efectiva en un $\mathrm{RN}$ pretérmino de 28 semanas, con la diferencia que emplearon un catéter Fogarty en el bronquio principal izquierdo.

\section{REFERENCIAS}

1. Rosero-Armijos V, Valverde-Palma L, Palma-Estrada CM, Cabrera-Jiménez FP, Ramírez-Amaya J. Complicaciones pulmonares asociadas a la ventilación mecánica en el neonato crítico. Recimundo. 2019; 3(4): 511-527.

2. Robert-Lee SY, Chiu-Shek Ch. Resolution of localized pulmonary interstitial emphysema in two neonates-whydoes neurally adjusted ventilatory assist work? J Clin Neonatol. 2015; 4 (2): 115-118.

3. Liszewski-MC, Lee-EY. Neonatal lung disorders: pattern recognition approach to diagnosis. Pediatric Imaging. 2018; 210: 964-975.

4. Deutsch $\mathrm{G}$. Trastornos adquiridos e idiopáticos en recién nacidos y niños pequeños. En: Zander-DS, Farver-CF. Patología pulmonar. 2nd ed. Barcelona: ELSEVIER; 2018. p. 61-80.

5. Bancalari E, Claure N, Jain D. Tratamiento respiratorio neonatal. En: Gleason-CA, Juul-SE. Avery. Enfermedades del recién nacido. 10 ed. Barcelona: ELSEVIER; 2019. p. 632-652.
6. Martínez-Rodríguez LP, Moreno-Gómez LA, Carrillo-Bayona JA, Rueda-Badillo EY. Lesiones pulmonares quísticas en el neonato: no todo es enfermedad congénita pulmonar. Reporte de caso. MÉD UIS. 2018; 31 (1): 65-70.

7. Lei X, Stangl O, Bosche Ch, Stuchlik K, Czorba R, Wieg Ch. Positional treatment without mechanical ventilation in a very preterm infant with unilateral pulmonary interstitial emphysema: case report and review of the literatura. BMC Pediatr. 2019; 19 (267).

8. Rent SM, Donn SM. Treatment of severe unilateral pulmonary interstitial emphysema in a preterm infant. Clin Case Rep Int. 2017; 1: 1019.

9. Huerta-Millán C, Lorenzo-Silva J, Zafra-Jiménez I, Gil-Willy W, Moscoso-Jaramillo MB. Ventilación mecánica selectiva (a un pulmón) y manejo anestésico en cirugía toracoscópica videoasistida. Rev Mex Anest. 2002; 25 (2): 102-109.

10. González-Alonso MV, Mesa-Riquelme LA, Domínguez-Dieppa F, Porto-Rodríguez AS. Tratamiento del enfisema intersticial pulmonar unilateral con ventilación monopulmonar contralateral. Presentación de un caso. Rev Cub Pediatr. 2008; 70 (2): 108-112.

11. Kauark-Amoedo M, Soares-Souza LV, Soares-Souza A, SoaresSouza A, Marchiori E. Pulmonary interstitial emphysema a case report and review of the literatura. Radiol Bras. 2013; 46 (5): 317-319.

Conflicto de intereses: los autores declaran que no tienen. 